\title{
Campus sewage treatment in multilayer horizontal subsurface flow constructed wetlands: Nitrogen removal and microbial community distribution
}

Shaoyuan Bai ${ }^{1,2}$, Tao Lyu ${ }^{3,4, *}$, Yanli Ding ${ }^{5, * *}$, Zhenling $\mathrm{Li}^{1,2}$, Dunqiu Wang ${ }^{1,2}$, Shaohong You ${ }^{1,2}$, and Qinglin $\mathrm{Xie}^{1,2}$

${ }^{1}$ Collaborative Innovation Center for Water Pollution Control and Water Safety in Karst Area, Guilin University of Technology, Guilin, China

${ }^{2}$ College of Earth Sciences, Guilin University of Technology, Guilin, China

${ }^{3}$ Department of Bioscience, Aarhus University, Aarhus, Denmark

${ }^{4}$ School of Animal, Rural and Environmental Sciences, Nottingham Trent University, Nottinghamshire, UK

${ }^{5}$ Guangxi Key Laboratory of Environmental Pollution Control Theory and Technology, Guilin University of Technology, Guilin, China

Correspondence, Dr. T. Lyu, School of Animal, Rural and Environmental Sciences, Nottingham Trent University, Nottinghamshire NG25 0QF, UK

Email: tao.lyu@ntu.ac.uk

((Dear Typesetter, please give as a footnote:))

Additional correspondence: Professor Y. Ding, email: dyl@glut.edu.cn

\begin{abstract}
Horizontal subsurface flow constructed wetlands (HSCWs) are widely used for wastewater treatment. The objective of this study was to assess the effects of substrate size selection and layout optimisation on pollutant removal and microbial community distribution responses in HSCWs. Three pilot-scale constructed wetlands (CWs) were established at Guilin University of Technology, China, to treat campus sewage. The three CWs included monolayer (CW1), three-layer (CW2), and six-layer (CW3) substrate structures with the hydraulic conductivity of the substrate increasing from the surface to the bottom in the multilayer CWs. Under an aerial influent loading rate of $0.38 \mathrm{~m}$ per day (volumetric loading rate of 0.63 per day), CW3 exhibited the highest removal performance for chemical oxygen demand (COD), $\mathrm{NH}_{4}{ }^{+}-\mathrm{N}$, and total nitrogen (TN), with mean values of 81, 81, and 74\%, respectively, followed by CW2 (68, 71, and $60 \%$, respectively) and $\mathrm{CW} 1(56,46$, and $41 \%$, respectively). Nitrification was demonstrated to be the limiting factor of TN removal, and higher TN removal performance in the multilayer CWs was attributed to the higher proportions of nitrifiers, including ammonia-oxidising bacteria (AOB) and nitriteoxidising bacteria (NOB). Moreover, 454-pyrosequencing showed a significantly different spatial distribution of the $\mathrm{N}$-transforming microbial community in multilayer HSCWs with substrate layout optimisation.
\end{abstract}

\section{Abbreviations}


ADB, autotrophic denitrification bacterium; ANOVA, analysis of variance; AOA, ammonia-oxidizing archaea; AOB, ammonia-oxidizing bacterium; COD, chemical oxygen demand; $\mathbf{C W}$, constructed wetland; HDB, heterotrophic denitrification bacterium; HRT, hydraulic retention time; HSFCW, horizontal subsurface flow constructed wetland; NOB, nitrite-oxidizing bacterium; ORP, oxidative reduction potential; OUT, operational taxonomic unit; PC, principal component; PCA, principal components analysis; TN, total nitrogen

Keywords: Campus wastewater, Multilayer constructed wetland, Nitrogen-transforming bacteria, Substrate structure

\section{Introduction}

Constructed wetlands (CWs), and especially horizontal subsurface flow constructed wetlands (HSCWs), are widely used for wastewater treatment owing to their low construction cost and simple management [1]. Secondary effluent from municipal wastewater treatment that is discharged into surface water natural end-receivers contains residual chemical oxygen demand (COD) and nitrogen (N) compounds. CWs can operate as 'pre-receivers' for the refinement of discharged wastewater [2]; however, dead zones and clogging are common, resulting in preferential pathways [3] that can limit contaminant transfer between aerobic, anoxic, and anaerobic zones in the wetland bed, which may decrease treatment performance. This poor hydrodynamic behaviour is commonly caused by improper $\mathrm{CW}$ design. Given the increasing application of CWs and increasingly strict water quality standards, there is a growing need to improve CW design.

Pollutant transformation and biodegradation in CWs mainly occurs in the substrate-associated biofilm, making the substrate one of the most important components responsible for pollutant removal in CWs [4, 5]. Previous studies have attempted to optimise substrate arrangement in HSCWs by incorporating granular heterogeneity to improve hydraulic performance, resulting in higher pollutant removal abilities [6]. Theoretically, the new configuration of substrate, which setting substrate with larger size and higher hydraulic conductivity at the bottom layers and substrate with smaller size and lower hydraulic conductivity at the above layers, can help to avoid the dead zones at the bottom and provide an even flow path in the wetland bed [7]. Finally, uniform water flow patterns would improve pollutant biodegradation owing to higher biofilm/pollutant contact. Following modelled simulations, a system incorporating this concept was built and was found to achieve higher pollutant removal over the short term [7]; however, the stability of treatment performance over long term operation, as well as the spatial characteristics of pollutant removal in multilayer $\mathrm{CW}$ s remains to be evaluated.

In $\mathrm{CWs}, \mathrm{N}$ removal primarily occurs through nitrification and denitrification [8]. Nitrification is mainly carried out by ammonia-oxidising bacteria (AOB) and nitrite-oxidising bacteria (NOB), which are capable of transforming ammonia directly to nitrite and nitrate, respectively. Denitrification consists of the transformation of nitrate or nitrite into gaseous forms by heterotrophic denitrification bacteria (HDB) and autotrophic denitrification bacteria (ADB) [9, 10]. In addition, anaerobic ammonium oxidation (Anammox) bacteria, which are capable of autotrophic ammonium oxidation with nitrite as the terminal electron acceptor in anoxic/anaerobic conditions, are also known to exist within CWs [11]; however, a 
better understanding of the spatial distribution of these $\mathrm{N}$-transforming microbial communities as a response to substrate layout optimisation is needed to improve our understanding of $\mathrm{N}$ removal mechanisms and to further refine the design and application of CWs.

The objectives of this study were to determine the effects of substrate size selection and layout optimisation on 1) the spatial characteristics of pollutant removal and on 2) microbial community distribution along the water flow path in three HSCWs. The study was carried out on one monolayer and two multilayer (three- and six-layer) pilot-scale HSCWs treating sewage from a university campus. 454pyrosequencing of the $16 \mathrm{~S}$ rRNA gene was conducted to determine the abundance and structure of the Ntransforming microbial community.

\section{Materials and methods}

\subsection{Experimental setup}

The present study was conducted in three parallel pilot-scale HSCWs, located at Guilin University of

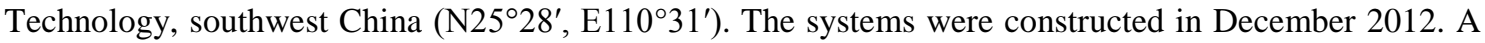
detailed description of the experimental setup can be found in Bai et al. [7]. Briefly, all systems were 2.0 $\mathrm{m}$ long, $1.2 \mathrm{~m}$ wide, $0.7 \mathrm{~m}$ high, and had a water depth of $0.6 \mathrm{~m}$ (Fig. 1). Each CW was divided into an influent distribution zone $(0.2 \mathrm{~m}$ long), a main reaction bed $(1.6 \mathrm{~m}$ long), and an effluent collection zone (0.2 $\mathrm{m}$ long). The three CWs differed in terms of the quartz sand size and layout (Supporting Information Table S1): 1) CW1 had a monolayer substrate of quartz sand (size: 0-6 mm; hydraulic conductivity $(K)$ : $65 \mathrm{~m}$ per day); 2) CW2 consisted of three equal layers, each $0.2 \mathrm{~m}$ thick, with $K$ values of 64,36 , and 26 $\mathrm{m}$ per day from the bottom layer to the surface layer; and the corresponding sand has diameters of 1--3, 0.4-0.6, and 0-0.4 mm, respectively; 3) CW3 comprised of six equal layers, each $0.1 \mathrm{~m}$ thick, with $K$ values of 176, 75, 55, 43 and $26 \mathrm{~m}$ per day from bottom layer to the surface layer, and corresponding sand sizes of 4--6, 2--4, 1--2, 0.6--0.9, 0.4--0.6 and 0-0.4 mm, respectively.

The experimental site was protected by a glass roof, in order to avoid the precipitation effect, but also received the natural variations in light exposure and temperature. The influent was real sewage generated by the university campus and pre-treated in a septic tank (Fig. 1). The three CWs shared a $200 \mathrm{~L}$ influent tank, and influent was controlled using a speed adjustable pump that maintained a flow rate of $0.72 \mathrm{~m}^{3}$ per day (areal loading rate of $0.38 \mathrm{~m}$ per day and volumetric loading rate of 0.63 per day). The physicochemical parameters of the influent pollutant concentrations and loading rate are shown in Table 1. For each CW, two PVC pipes were placed $0.4 \mathrm{~m}$ (W1) and $1.6 \mathrm{~m}$ (W2) away from the influent at a depth of $0.4 \mathrm{~m}$ from the top of the system (Fig. 1). All PVC pipes were equipped with valves for water sampling. Canna indica, the macrophyte species chosen for analysis, was introduced at a density of 20 strains per $\mathrm{m}^{2}$. The study was conducted in the summer (1 May to 31 July 2015), when the air temperature ranged from 17 to $30^{\circ} \mathrm{C}$. These systems had previously run for approximately two years under the same operational conditions.

\subsection{Water sampling and analysis}

During the 12 weeks' experimental period, water samples (500 mL each) were collected from all CWs once a week. Each CW had four water sampling locations (triplicate for each site), including the influent, 
effluent, and two sampling pipe valves (W1 and W2 in Fig. 1). The temperature, pH, and oxidation reduction potential (ORP) were measured in situ by a multi-parameter portable meter (HANNA HI9828). Water samples were stored in sterile plastic bottles and transported under cooling conditions $\left(5^{\circ} \mathrm{C}\right)$ to the laboratory for $\mathrm{COD}, \mathrm{NH}_{4}{ }^{+}-\mathrm{N}, \mathrm{NO}_{3}{ }^{--}-\mathrm{N}, \mathrm{NO}_{2}^{---}-\mathrm{N}$, and $\mathrm{TN}$ analysis within $24 \mathrm{~h}$ using standard methods of APHA [12].

\subsection{Substrate sampling and analysis}

\subsubsection{Sampling}

Samples of substrate for 454-pyrosequencing analyses were collected at the end of the study (31 July 2015 ) using a push core sampler ( $\varnothing 5 \mathrm{~cm}, 100 \mathrm{~cm}$ in length). At each CW, substrate samples were taken from locations at 0.4 and $1.6 \mathrm{~m}$ from the influent ( $\mathrm{S} 1$ and S2 in Fig. 1), at a depth of $\sim 0.4 \mathrm{~m}$. After removing visible roots and debris, samples were stored in sterile plastic bags, placed on ice, and transferred immediately to the laboratory. Each substrate sample was then homogenised (i.e., mixed) manually and divided into three replicates. A total of 18 samples were used for the analyses of microbial communities.

\subsubsection{DNA extraction}

DNA was extracted from $0.5 \mathrm{~g}$ of each substrate sample using the PowerSoil DNA Isolation Kit (MoBio, USA) according to the manufacturer's protocols. Extracted genomic DNA was detected by using $1 \%$ agarose gel electrophoresis to examine its integrity and approximate concentration.

\subsubsection{Pyrosequencing and Illumina high-throughput sequencing}

Pyrosequencing and Illumina high-throughput sequencing were conducted at Sangon Biotech (Shanghai, China). Microbial DNA was amplified using a set of primers targeting the V3 + V4 hypervariable region (approximately $440 \mathrm{bp}$ ) of the $16 \mathrm{~S}$ rRNA gene before pyrosequencing. The forward primer was $515 \mathrm{~F}$ (GTGCCAGCMGCCGCGGTAA) and the reverse primer was 909R (CCCCGYCAATTCMTTTRAGT). The 16S rRNA gene sequencing obtained from the Illumina MiSeq $2 \times 300 \mathrm{bp}$ and the raw data were quality checked in Prinseq. To compare samples at the same sequencing depth, normalisation of the sequence number was conducted by randomly extracting at least 40000 sequences from each sample for subsequent analysis using the Mothur software package (v.1.30.1). After removing barcodes and primers, the sequences were assigned at different taxonomic levels (from domain to genus) based on comparison to the SILVA dataset. High-quality sequences were processed using Uclust to generate operational taxonomic units (OTUs) with a 97\% sequence similarity threshold. The abundance and diversity of microorganisms were classified using the RDF Classifier, which is based on Bergey's taxonomy at the genus level.

\subsection{Statistical analyses}

Comparison of COD, $\mathrm{NH}_{4}{ }^{+}-\mathrm{N}$, and TN concentrations among the sample sites were performed using one- 
way analysis of variance (ANOVA). The N-transforming microbial community distribution was analysed and visualised through principal components analysis (PCA). Both ANOVA and PCA were run using the SPSS.21 software package (Boston, Mass: International Business Machines, 2012).

\section{Results and Discussion}

\subsection{Pollutant removal and water quality}

The ORP increased from influent (mean $-158 \mathrm{mV}$ ) to effluent (range $=-91$ to $-111 \mathrm{mV}$ ). The improved oxidation potential of the water may reflect natural oxygen diffusion from the air and the oxygen release function of wetland plants. However, it should be noticed that the effluent is the composite sample mixed by the water from the whole CW. The HSFCWs always present different ORP in different wetland bed layers, which is higher in the top layers than in the bottom [13]. Moreover, the oxygen can be pumped into the wetlands by plant roots and form the micro aerobic-anoxic-anaerobic environment near the rhizosphere, which may still provide a suitable condition for nitrification and denitrification process [14]. Thus, further analysis of the nitrogen transforming microbial community was conducted by the molecular biology method in the present study and explained below (Sections 3.3 and 3.4). The mean effluent $\mathrm{pH}$ values of the three CWs were $\sim 7.3$ and showed no significant differences with the influent. The stable $\mathrm{pH}$ values indicate the potential buffer capacity of $\mathrm{CWs}$ during wastewater treatment. Notably, the $\mathrm{pH}$ and ORP were not significantly different between of the three CWs, suggesting that multilayer CWs do not influence water quality for campus sewage treatment.

At sampling position W1, CW2 and CW3 showed higher removal efficiencies (43 to 52\%) of COD and $\mathrm{NH}_{4}{ }^{+}-\mathrm{N}$ than did CW1 (26 to 33\%); however, the TN removal efficiencies of all three CWs were similar (16 to 19\%) at W1 (Fig. 2). The removal of these pollutants showed similar patterns for all CWs, significantly increasing from sampling position $\mathrm{W} 1$ (16 to 52\%) to position W2 (38 to 78\%). The removal efficiencies of $\mathrm{COD}$ and $\mathrm{NH}_{4}{ }^{+}-\mathrm{N}$ were not further increased from $\mathrm{W} 2$ to the effluent; however, TN removal efficiencies improved significantly from W2 to the effluent. Overall, generally significantly higher removal efficiencies of COD, $\mathrm{NH}_{4}{ }^{+}-\mathrm{N}$, and TN were achieved in CW3 (means of 81, 82, and 76\%, respectively), followed by CW2 (means of 69, 71, and 67\%, respectively) and CW1 (means of 56, 47, and $49 \%$, respectively).

The significantly better treatment performances of CW3 and CW2 indicated that a multilayer substrate layout in HSCWs can be a benefit for the removal of pollutants, including both COD and N. Wetland substrate layout optimisation by decreasing particle size from bottom to top may change the hydraulic conditions of the HSCWs and achieve more homogenised water flow and fewer water flow short-cuts [15]. In this case, COD and $\mathrm{N}$ removal through microbial biodegradation should significantly increase owing to enhanced pollutant--microbial contact [16]. The higher pollutant removal abilities of CW3, which has a multilayer substrate layout, may reflect more homogenised water flow in the wetland bed. Moreover, the multilayer configured wetland may also cause higher filtration capacity for the solid pollutants removal.

\subsection{Nitrogen mass balance}

Nitrogen mass balance (Fig. 3) showed that for all three CWs the proportion of $\mathrm{NH}_{4}{ }^{+}-\mathrm{N}$ decreased 
significantly from influent to W2 and then continued to decrease slowly until the effluent. In contrast, the $\mathrm{NO}_{3}{ }^{-} \mathrm{N}$ percentage clearly increased from influent (3\%) to $\mathrm{W} 1(20-30 \%)$, and then declined progressively until the effluent reached $<3 \%$ contribution $\left(<0.9 \mathrm{mg} \mathrm{L}^{-1}\right)$ in all CWs. For $\mathrm{NO}_{2}{ }^{-} \mathrm{N}$, percentages remained below $0.3 \%$ while concentrations remained $<0.1 \mathrm{mg} \mathrm{L}^{-1}$ for all samples throughout the study. The difference between $\mathrm{TN}$ and all other inorganic $\mathrm{N}$ species was considered to reflect mainly organic and particulate $\mathrm{N}$ forms, which showed a clear decrease from influent to $\mathrm{W} 1$ and then remained relatively stable along the remaining length of all $\mathrm{CWs}$.

Nitrification and denitrification, which can transform $\mathrm{NH}_{4}{ }^{+}-\mathrm{N}$ to $\mathrm{NO}_{3}{ }^{-} \mathrm{N}$ (nitrification) and then into gaseous $\mathrm{N}$ (denitrification) to achieve final $\mathrm{N}$ removal, can play a crucial role in $\mathrm{TN}$ removal from CWs [17]. Previous studies have shown that rapid $\mathrm{NH}_{4}{ }^{+}-\mathrm{N}$ removal through nitrification mainly occurs within the front of wetland beds in traditional HSCWs, due to the initial amount of oxygen content from the influent. The high initial oxidation reduces the available oxygen for continued reactions further along the bed [18]. Here, the $\mathrm{NH}_{4}{ }^{+}-\mathrm{N}$ removal from the front section (influent to W1) of the CWs was accompanied by significant increases in $\mathrm{NO}_{3}{ }^{-}-\mathrm{N}$ mass contributions (Fig. 3). This process resulted in similar TN removal for all CWs at W1 (Fig. 2). Similarly, easily degradable organic and particulate N may also degrade in the front part owing to the better aerobic conditions. The residue contents were not further removed in the CWs and do not contribute to TN removal, reflecting the recalcitrant $\mathrm{N}$. In the back part of $\mathrm{CWs}, \mathrm{NO}_{3}{ }^{-}-\mathrm{N}$ concentrations significantly decreased to $<0.9 \mathrm{mg} \mathrm{L}^{-1}$ at the effluent for all $\mathrm{CWs}$, which may indicate thorough denitrification under relatively anaerobic conditions. Simultaneously, slowed $\mathrm{NH}_{4}{ }^{+}-\mathrm{N}$ removal in this section supports the hypothesis that nitrification is the limiting process for TN removal owing to reduced oxygenation.

\subsection{Microbial community abundance and distribution}

Nitrifiers (AOB \& NOB), denitrifiers (HDB and ADB), and Anammox bacteria were detected in all substrate samples. In total, 40000 high-quality gene sequences were obtained from each sample and the classified OTUs ranged from 9830 to 11008. Rarefaction curves based on the OTUs at $3 \%$ dissimilarity (Supporting Information Fig. S1) indicated that the sequences were sufficient to reflect the diversity of the microbial communities. Thereof, around 1000 OTUs $(\sim 10 \%$ of the total $)$ in each $\mathrm{CW}$ were $\mathrm{N}$ transforming bacterial strains.

$\mathrm{AOB} \& \mathrm{NOB}, \mathrm{HDB}$ and $\mathrm{ADB}$ were found to be the main N-transforming microbial communities (2 to $8 \%$ of the total OTUs; Fig. 4), which supports the theory that nitrification and denitrification were the main N-removal processes in all CWs. Moreover, denitrifiers (the sum of HDB and ADB) showed clearly higher OTU compositions than nitrifiers (the sum of AOB and NOB) in all CWs, supporting the theory that denitrifying bacteria were more abundant than nitrifiers. It can be explained by the overall anoxic condition (effluent ORP of around $-100 \mathrm{mV}$ ) in the three wetland beds, which was suitable for the growth of denitrifiers. However, the presence, even though lower amount, of nitrifiers in the CWs may be due to the micro aerobic-anoxic-anaerobic environment near the rhizosphere created by the oxygen pumping function of the plant roots. On this basis, nitrification, not denitrification, may be the key factor in limiting TN removal. At sampling site S1, nitrifiers in multilayer CWs (165-182 OTUs) were higher than in the monolayer CW (141 OTUs); therefore, higher TN removal (Fig. 2) may reflect a greater abundance 
of nitrifiers in multilayer CWs (CW2 and CW3), which can promote higher $\mathrm{NO}_{3}{ }^{-} \mathrm{N}$ through nitrification followed by removal through denitrification. Anammox bacteria only showed $4-11$ OTUs $(<0.5 \%$ of the total) in all samples, which indicates that Anammox bacteria could exist in CWs as a potential microbial route for equivalent close-coupled nitrification-denitrification; however, given the relatively limited abundance compared with other functional bacterial strains, their contribution toward $\mathrm{N}$ removal in the present study was relatively small.

The spatial distribution of the N-transforming microbial community among the three CWs at different sampling sites was interpreted using PCA (Fig. 5). The first two principal components (PCs) accounted for 82.79 and $15.72 \%$ of the total variation. Nitrifiers (AOB and NOB) mainly contributed to both positive PC1 and PC2. HDB clearly contributed more to the positive direction of PC1; however, ADB mainly contributed to the negative direction of PC2. Moreover, the short loading factor line of Anammox confirmed the low contribution ability of Anammox. Samples from S1 and S2 of each CW group showed significant differences. For S1, nitrifiers and HDB were most abundant in CW3, followed by CW2 and CW1. This clearly confirms a shift in the spatial distribution of N-transforming microbial communities in CW2 and CW3. In CW3, the ADB contribution increased along the direction of water flow until it replaced HDB as the dominant denitrifier. This change may have been caused by higher COD removal that resulted in insufficient carbon for heterotrophic denitrification (Fig. 2). As suggested by previous studies, microbial communities from different sites within CWs are specialised for their environment. They are fundamentally distinct from each other and exhibit significant spatial variations [8]. The results indicate that substrate layout optimisation in CWs could shift the position of N-transforming microbial communities, which could further improve TN removal abilities.

\subsection{Microbial community structure and distribution}

In each of the CWs, the microbial communities showed high diversity from phylum to genus level. Microbial DNA could be assigned to three major (relative abundance $>10 \%$ ) phylum, ten classes, 14 orders, 15 families, and 20 genera. Among them, the relative abundances of AOB \& NOB, HDB, ADB and Anammox bacterial species at the genus level are further analysed and presented in Fig. 6.

\subsubsection{Nitrifiers (AOB and NOB)}

For all CWs, the most abundant genus was Nitrospira (38 to 57\%), followed by Nitrosomonas (19 to $49 \%)$ and Nitrosococcus (10 to $36 \%)$. In contrast, only very few $(<0.3 \%)$ Nitrososphaera were detected (Fig. 6). Nitrosococcus and Nitrosomonas are well known as AOB and have been considered the most important contributors to aerobic ammonia oxidation [19]. Nitrospira is a known NOB because it can transform $\mathrm{NO}_{2}{ }^{-}-\mathrm{N}$ to $\mathrm{NO}_{3}{ }^{-}-\mathrm{N}$, and then eliminate the toxic effects of accumulated $\mathrm{NO}_{2}{ }^{--}-\mathrm{N}$ [19].

Nitrosococcus (AOB) dominated at S2 for CW2; although, its abundance was much lower at the other sampling sites for all CWs. Nitrosomonas (AOB) dominated at S1 for both CW2 and CW3, but not CW1. Previous studies have shown that ammonium oxidation is the rate-limiting step of nitrification compared with nitrite oxidation [20]. As AOB (the sum of Nitrosomonas and Nitrospira) exhibited higher abundances in CW2 and CW3 (as compare with CW1), it contributed to the higher ammonium removal efficiency. 


\subsubsection{Denitrifiers (HDB and ADB)}

The HDB bacteria were dominated by Denitratisoma (28 to 62\%), Rhizobium (8 to $42 \%$ ), Thauera (4 to $14 \%$ ), Acidovorax (4 to 16\%), Comamonas (1 to 13\%), and Rhodobacter (4 to 11\%). Other groups showed lower and comparable proportions in HDB (<5\%; Fig. 6). The two dominant HDBs (Denitratisoma and Thauera) belong to the Rhodocyclaceae family, members which are frequently found in wastewater heterotrophic denitrifying communities [21]. Thauera has been found with many hydrogenoxidising autotrophic denitrifying microbial communities, indicating that it can grow autotrophically [9], which is consistent with its relatively high abundance at $\mathrm{S} 1$, where organic matter was abundant for all CWs.

The genera associated with ADB were Thiobacillus and Sulfurimonas. Thiobacillus denitrificans and Sulfurimonas denitrificans (formerly known as Thiomicrospira denitrificans) are the most commonly reported ADB strains [22, 23], and Thiobacillus was dominant (>90\%) in all samples. This finding shows that combined heterotrophic and autotrophic denitrification processes can be attributed to $\mathrm{N}$ removal in HSCWs. Moreover, Thiobacillus and Thauera are dominant bacterial strains that cooperatively fulfil a simultaneous denitrification process [24]. The ADB abundances showed no significant differences between sampling sites $\mathrm{S} 1$ and $\mathrm{S} 2$, or between the different CWs.

\subsubsection{Anammox}

Candidatus Brocadia and Candidatus Anammoximicrobium, both Planctomycetes, are commonly known to be capable of denitrifying nitrogenous compounds using ammonium as an electron donor and $\mathrm{NO}_{2}{ }^{-}$as an electron acceptor under anoxic/anaerobic conditions [22, 25]. This process is often acknowledged to be a short circuiting pathway that normally requires relatively low oxygen and organic carbon. Here, the above two Anammox bacteria were detected in all samples, with Candidatus Brocadia more abundant, especially in $\mathrm{CW} 2$ and $\mathrm{CW} 3$. This result supports the potential for a $\mathrm{NH}_{4}{ }^{+}-\mathrm{N}$ depuration pathway from the reaction of Anammox; however, the contribution of Anammox to TN removal requires further study.

\section{Conclusions}

This study investigated the influence of substrate size selection and layout optimisation on pollutant removal and microbial community characteristics in CWs. The multilayer CWs, in which the hydraulic conductivity of the substrate decreased from the bottom to surface, exhibited significantly higher removal ability of COD, $\mathrm{NH}_{4}{ }^{+}-\mathrm{N}$, and TN. Nitrification was demonstrated to be the limiting factor of TN removal in HSCWs. The higher TN removal performance in multilayer CWs was attributed to the higher proportions of nitrifiers (AOB and $\mathrm{NOB}$ ). Moreover, clear differences in the abundance, structure, and spatial distribution of $\mathrm{N}$-transforming microbial communities were observed between multilayer and monolayer CWs. HDB tended to be more abundant in the first part of CWs, while ADB was more abundant in the end part of multilayer HSCWs.

\section{Acknowledgements}

The present study was supported by Guangxi Natural Science Foundation (No. 2014GXNSFBA118234, 
2015DD25042Guikehe1599005-2-2), the National Natural Science Foundation of China (No. 51408147, 41404116), and was also funded by Guangxi Scientific Experiment Center of Mining, Metallurgy and Environment and the project of high level innovation team and standing scholar in Guangxi colleges and universities.

The authors have declared no conflict of interest.

\section{References}

[1] J. Vymazal, Horizontal sub-surface flow constructed wetlands Ondrejov and Spalene Porıc1 in the Czech Republic - 15 years of operation, Desalination 2009, 246, 226--237.

[2] E. Trulli, V. Torretta. E.C. Rada, Water restoration of an urbanized karst stream by Free-WaterSurface Constructed Wetlands as municipal wastewater post-treatment, UPB Sci. Bull., Ser. D 2016, 78 (4), 163--174.

[3] H. Brix, O. Koottatep, T. Fryd, C. H. Laugesen, The flower and the butterfly constructed wetland system at Koh Phi Phi -- System design and lessons learned during implementation and operation, Ecol. Eng. 2011, 37 (5), 729--735.

[4] C. A. Prochaska, A. I. Zouboulis, Treatment performance variation at different depths within vertical subsurface-flow experimental wetlands fed with simulated domestic sewage, Desalination 2009, $237(1--3), 367--377$.

[5] T. Lv, P.N. Carvalho, L. Zhang, Y. Zhang, M. Button, C.A. Arias, K. P. Weber, H. Brix, Functionality of microbial communities in constructed wetlands used for pesticide remediation: Influence of system design and sampling strategy, Water Res. 2017, 110, 241--251.

[6] J. García, P. Aguirre, J. Barragán, R. Mujeriego, V. Matamoros, J. M. Bayona, Effect of key design parameters on the efficiency of horizontal subsurface flow constructed wetlands, Ecol. Eng. 2005, $25,405-418$.

[7] S. Bai, T. Lv, Y. Ding, X. Li, S. You, Q. Xie, H. Brix, Multilayer substrate configuration enhances removal efficiency of pollutants in constructed wetlands, Water 2016, 8 (12), w8120556.

[8] H. Deng, L. Ge, T. Xu, M. Zhang, X. Wang, Y. Zhang, H. Peng, Analysis of the metabolic utilization of carbon sources and potential functional diversity of the bacterial community in lab-scale horizontal subsurface-flow constructed wetlands, J. Environ. Qual. 2011, 40 (6), 1730--1736.

[9] Y. Mao, Y. Xia, T. Zhang, Characterization of Thauera-dominated hydrogen-oxidizing autotrophic denitrifying microbial communities by using high-throughput sequencing, Bioresour. Technol. 2013, $128,703-710$.

[10] T. Zhang, L. Ye, A. Tong, M. Shao, S. Lok, Ammonia-oxidizing archaea and ammonia-oxidizing bacteria in six full-scale wastewater treatment bioreactors, Appl. Microbiol. Biotechnol. 2011, 91 (4), 1215--1225.

[11] Z. Dong, T. Sun, A potential new process for improving nitrogen removal in constructed wetlands -Promoting coexistence of partial-nitrification and ANAMMOX, Ecol. Eng. 2007, 31 (2), 69--78.

[12] APHA, AWWA, WEF, Standard Methods for the Examination of Water and Wastewater, 20th Ed., American Public Health Association, Washington, DC 1998. 
[13] H. Brix, Do macrophytes play a role in constructed wetlands?, Water Sci. Technol. 1997, 35 (5), 11-17.

[14] R. H. Kadlec, S. Wallace, Treatment Wetlands, CRC Press/Lewis Publishers, Boca Raton, FL, USA 2008.

[15] F. Suliman, C. Futsaether, U. Oxaal, Hydraulic performance of horizontal subsurface flow constructed wetlands for different strategies of filling the filter medium into the filter basin, Ecol. Eng. 2007, 29 (1), 45--55.

[16] H. C. Tee, P. E. Lim, C. E. Seng, M. A. M Nawi, Newly developed baffled subsurface-flow constructed wetland for the enhancement of nitrogen removal, Bioresour. Technol. 2012, 104 (1), $235-242$.

[17] G. Sun, Y. Zhu, T. Saeed, G. Zhang, X. Lu, Nitrogen removal and microbial community profiles in six wetland columns receiving high ammonia load, Chem. Eng. J. 2012, 203, 326--332.

[18] J. F. Martin, K. R. Reddy, Interaction and spatial distribution of wetland nitrogen processes, Ecol. Model. 1997, 105, 1--21.

[19] D. Shu, Y. He, H. Yue, Q. Wang, Microbial structures and community functions of anaerobic sludge in six full-scale wastewater treatment plants as revealed by 454 high-throughput pyrosequencing, Bioresour. Technol. 2015, 186, 163-172.

[20] F. Zhong, J. Wu, Y. Dai, L. Yang, Z. Zhang, S. Cheng, Q. Zhang, Bacterial community analysis by PCR-DGGE and 454-pyrosequencing of horizontal subsurface flow constructed wetlands with front aeration, Appl. Microbiol. Biotechnol. 2015, 99, 1499--1512.

[21] X. Hong, X. Zhang, B. Liu, Y. Mao, Y. Liu, L. Zhao, Structural differentiation of bacterial communities in indole-degrading bioreactors under denitrifying and sulfate-reducing conditions, Res. Microbiol. 2010, 161 (8), 687--693.

[22] L. Niftrik, M. Jetten, Anaerobic ammonium-oxidizing bacteria: unique microorganisms with exceptional properties, Microbiol. Mol. Biol. Rev. 2012, 76 (3), 585--596.

[23] M. Shao, T. Zhang, H. Fang, Sulfur-driven autotrophic denitrification: diversity, biochemistry, and engineering applications, Appl. Microbiol. Biotechnol. 2010, 88 (5), 1027--1042.

[24] G. Xu, J. Peng, C. Feng, F. Fang, S. Chen, Y. Xu, X. Wang, Evaluation of simultaneous autotrophic and heterotrophic denitrification processes and bacterial community structure analysis, Appl. Microbiol. Biotechnol. 2015, 99, 6527-6536.

[25] L. Shen, H. S. Wu, Z. Q. Gao, H. X. Cheng, J. Li, X. Liu, Q. Q. Ren, Distribution and activity of anaerobic ammonium-oxidising bacteria in natural freshwater wetland soils, Appl. Microbiol. Biotechnol, 2016, 100, 3291-3300.

Table 1. Physicochemical parameters of the influent

\begin{tabular}{|c|c|c|c|}
\hline Parameter & $\begin{array}{l}\text { Value } \\
\left(\mathrm{mg} \mathrm{L} \mathbf{L}^{-1}\right)\end{array}$ & $\begin{array}{l}\text { Areal loading rate } \\
\text { (g m--2- per day) }\end{array}$ & $\begin{array}{l}\text { Volumetric loading rate } \\
\text { ( } \mathrm{g} \mathrm{m}^{-3} \text { per day) }\end{array}$ \\
\hline Water temperature $\left({ }^{\circ} \mathrm{C}\right)$ & $21 \pm 7$ & -- & $\begin{array}{ll}-- \\
-1\end{array}$ \\
\hline $\mathrm{pH}$ & $7.3 \pm 0.3$ & -- & -- \\
\hline DO & $1.3 \pm 0.3$ & -- & -- \\
\hline
\end{tabular}




\begin{tabular}{llll}
$\mathrm{ORP}$ & $--158 \pm 30$ & -- & -- \\
$\mathrm{COD}$ & $145 \pm 36$ & $54 \pm 14$ & $91 \pm 23$ \\
$\mathrm{NH}_{4}{ }^{+}-\mathrm{N}$ & $23 \pm 10$ & $9 \pm 4$ & $14 \pm 6$ \\
$\mathrm{NO}_{3}{ }^{--}-\mathrm{N}$ & $0.9 \pm 0.8$ & $0.3 \pm 0.3$ & $0.6 \pm 0.5$ \\
$\mathrm{NO}_{2}{ }^{--}-\mathrm{N}$ & $\leq 0.1$ & $\leq 0.04$ & $\leq 0.06$ \\
$\mathrm{TN}$ & $32 \pm 8$ & $12 \pm 3$ & $20 \pm 5$ \\
\hline
\end{tabular}

\section{Figure legends}

Figure 1. Schematic diagram of monolayer (CW1) and multilayer (CW2, CW3) pilot-scale HSCWs for treating campus sewage. Red dots represent water (W) and substrate (S) sampling sites.

Figure 2. Removal efficiencies of chemical oxygen demand (COD; \%), $\mathrm{NH}_{4}{ }^{+}-\mathrm{N}(\%)$, and TN (\%) along wetland beds (W1-W2-out) in constructed wetland 1 (CW1; blue bars), CW2 (red bars), and CW3 (green bars). Error bars indicate standard variation. Letters above bars denote the significant difference.

Figure 3. Mass balance of different $\mathrm{N}$ species $\left(\mathrm{NH}_{4}{ }^{+}-\mathrm{N}=\right.$ blue bars; $\mathrm{NO}_{3}{ }^{--}-\mathrm{N}=$ red bars; $\mathrm{NO}_{2}{ }^{-}-\mathrm{N}=$ black bars; sum of organic and particulate $\mathrm{N}=$ green bars; removed $\mathrm{N}=$ grey bars) in each sampling site along wetland beds (In-W1-W2-out) of (a) CW1, (b) CW2, and (c) CW3. Mass balances were calculated from mean values. The sum of organic and particulate $\mathrm{N}$ was calculated as the difference between TN and all other inorganic $\mathrm{N}$ species.

Figure 4. OTUs of each N-transforming microbial community in substrate samples S1 and S2 for constructed wetland 1 (CW1), (b) CW2, and (c) CW3. Error bars indicate standard variation. Blue bars denote AOB, red bars denote NOB, green bars denote ADB, and grey bars denote Anammox.

Figure 5. PC (black circles) analysis of the relationships between sampling locations and relative abundance of each N-transforming microbial community OTUs in substrate samples (coloured circles = $\mathrm{S} 1$, coloured squares $=\mathrm{S} 2)$ of the three constructed wetlands $(\mathrm{CW} 1=$ blue symbols, $\mathrm{CW} 2=$ yellow symbols; CW3 = red symbols). Arrows represent the loading factors of each variable.

Figure 6. Relative abundances $(\%)$ of $\mathrm{N}$-transforming microbial genus (see colour scale on figure) in different substrate samples (S1 and S2) for (a) constructed wetland 1 (CW1), (b) CW2, and (c) CW3. 